\title{
Impacto das ondulações transversais na qualidade do transporte público coletivo na cidade de Cuiabá, Mato Grosso, Brasil
}

\section{The impact of speed bumps on the quality of public transportation in the city of Cuiabá, Mato Grosso, Brazil / MT}

\author{
${ }^{1}$ Priscila Elias Correa, ${ }^{2}$ Marina Leite de Barros Baltar, ${ }^{3}$ Juliane Érika Bender Cavalcante, ${ }^{4}$ Dr. Raoni Florentino \\ da Silva Teixeira.
}

${ }^{1}$ Graduanda em Engenharia de Transportes - Universidade Federal de Mato Grosso (priecm@ gmail.com). ${ }^{2}$ Professora Efetiva de Engenharia de Transportes - Universidade Federal de Mato Grosso (mabaltar@gmail.com). 3Professor Efetiva de Engenharia de Transportes - Centro Federal de Educação Tecnológica de Minas Gerais (bender@pet.coppe.ufrj.br).

${ }^{4}$ Dr. Raoni Florentino da Silva Teixeira - Professor Dr. Adjunto da UFMT do campus de Várzea Grande (raonifst@gmail.com).

\begin{abstract}
RESUMO: Entender quais fatores afetam a qualidade do transporte público aumenta a probabilidade de acertos no planejamento viário urbano, melhorando assim a experiência diária dos passageiros. O deslocamento é uma parte necessária para qualquer atividade a ser realizada fora da residência do indivíduo. Assim, a qualidade do serviço de transporte ofertado interfere no tempo gasto e na saúde física e psicológica de seus usuários. Atualmente, a cidade de Cuiabá, capital de Mato Grosso, enfrenta problemas com a construção irregular de ondulações transversais, também conhecidas como lombadas, principalmente em vias definidas como rota do transporte coletivo por ônibus, o que pode impactar diretamente na qualidade do serviço. Este trabalho tem como objetivo analisar as possíveis implicações das lombadas na qualidade do serviço de transporte público coletivo oferecido na cidade de Cuiabá-MT. Elaborou-se para isso uma pesquisa de satisfação junto os usuários destes serviços. Complementarmente, mesurou-se o impacto operacional das lombadas no tempo de viagem dos ônibus através de um levantamento de campo, utilizando-se imagens captadas por meio de uma Aeronave Remotamente Pilotada (RPA) conhecida por drone. De forma geral, pode- se afirmar que os usuários percebem uma piora em sua experiência no transporte público ao passarem por lombadas. A medição de campo indicou que elas reduzem a velocidade de serviço e aumentam o tempo viagem efetivo.
\end{abstract}

Palavras-chave: Transporte público. Lombadas. Visão do usuário.

\begin{abstract}
Understanding which factors affect the public transport quality increases the probability of correct urban road planning, thus improving the passengers' daily experience. Travel is a necessary part of any activity to be performed outside the individual's home. Thus, the offered transport service quality interferes with the time spent and the physical and psychological health of its users. Currently, Cuiabá city, capital of Mato Grosso, faces problems with the irregular construction of speed bumps, mainly on roads defined as public transport routes, which can directly impact the service quality. This work aims to analyze the possible implications of speed bumps on the public transport quality service offered in Cuiabá-MT. For this, a satisfaction survey with users of these services was prepared. In addition, the operational impact of speed bumps on the travel time of buses was measured through a field survey, using images captured by a Remotely Piloted Aircraft (RPA) known as a drone. In general, it can be said that users notice a worsening in their experience on public transport when they go through speed bumps. Field measurement indicated that they reduce service speed and increase effective travel time.
\end{abstract}

Keywords: Public transport. Speed Bumps. User view.

\section{INTRODUÇÃO}

Segundo a Organização das Nações Unidas (ONU, 2016), as cidades precisam ter um sistema de transporte público atraente e acessível, tanto geograficamente quanto financeiramente, de forma a reduzir a dependência do veículo motorizado particular. No que tange a qualidade do transporte público como um todo, podem ser analisados os seguintes 
aspectos: confiabilidade, segurança, estado das vias, frequência no atendimento e tempo de viagem.

Medir a qualidade do transporte público é uma tarefa importante, visto que, com isso, é possível traçar melhores soluções que atendam aos critérios adequados para os usuários, que são aqueles que mais sentem as ineficiências, ao mesmo tempo que são os principais julgadores do transporte público. Neste aspecto, alguns critérios são importantes para mensurar a qualidade do transporte público.

A confiabilidade está relacionada ao cumprimento dos horários pré-estabelecidos, tanto da chegada do veículo ao ponto de embarque quanto o horário de chegada ao ponto de desembarque, dentro de uma tolerância aceitável de tempo. Em outras palavras, a confiabilidade está ligada à frequência com que a linha passa pelo ponto de parada, um serviço que deve ser realizado com exatidão, com cumprimento de itinerário e cumprindo o tempo de viagem (FERRAZ; TORRES, 2004).

O tempo de viagem é o tempo gasto dentro dos veículos e depende da velocidade média de transporte e distância percorrida entre os locais de embarque/desembarque. Outros fatores como a distância entre os pontos de embarque/desembarque, a segregação das vias, condições da pista de rolamento, trânsito e tecnologia dos veículos também interferem no tempo de viagem.

A velocidade média de percurso é um parâmetro que afeta diretamente o tempo de viagem e, conforme Associação Nacional das Empresas de Transportes Urbanos (NTU, 2018), é um fator importante para avaliar o desempenho do transporte, pois interfere na frequência e nos custos operacionais do sistema. Além disso, a perda da velocidade comercial pode acarretar aumento tarifário, contribuindo para a insatisfação do usuário ou até mesmo incentivando sua fuga para outros meios de transporte.

Segundo o Transportation Research Board (TRB, 2010), a velocidade é um meio de avaliar o nível de serviço de tráfego da via, sendo um dos parâmetros base para definição da capacidade da mesma. Para Cupolillo (2006), a velocidade desenvolvida dentro das cidades e nas rodovias é influenciada pelo fator humano, isto é, depende do motorista, e pelas características físicas da via, como sua classe, estado de conservação, limitadores de velocidade (lombadas e semáforos), condições de tempo e visibilidade. Portanto, este parâmetro pode ser afetado pelos congestionamentos, quando a capacidade da via é atingida, e, também, pela quantidade de frenagens e acelerações necessárias para percorrer o trecho.

Em um levantamento disponibilizado aos autores pela Associação Mato-grossense dos Transportes Urbanos (AMTU) revela uma grande quantidade de lombadas pelas quais os ônibus que trafegam pela cidade de Cuiabá, capital do Estado de Mato Grosso, ficam submetidos diariamente. Motoristas de 83 linhas registraram a quantidade que passavam durante o dia, a quilometragem percorrida e a quantidade de viagens e, a partir desses dados, foi criada uma tabela resumo com todas essas informações apresentadas no Quadro 1. Adiciona-se que a grande maioria das lombadas pelas quais os veículos são submetidos estão localizadas no interior dos bairros. 
Correa, E. P.; Baltar, M.; Cavalcante, J.; O impacto das ondulações transversais na qualidade do transporte público coletivo na cidade de Cuiabá, Mato Grosso, Brasil. E\&S - Engineering and Science, 2021, 10:2.

Quadro 1 - Quantidade de lombadas por linha de ônibus.

\begin{tabular}{llccccc}
\hline Linha & \multicolumn{1}{c}{ Denominação } & $\begin{array}{c}\text { Extensão } \\
(\mathbf{k m})\end{array}$ & & Dia útil (DU) & \multicolumn{2}{c}{$\begin{array}{c}\text { Lombadas/ } \\
\text { viagem }\end{array}$} \\
\hline & & & Frota & Viagens & Km/dia & \\
\hline 517 & Santa Laura - Centro & 44,10 & 09 & 59 & 2.623 & 128 \\
501 & São Sebastião - Centro & 41,90 & 03 & 20 & 838 & 110 \\
503 & Osmar Cabral - Rodoviária & 38,50 & 04 & 21 & 808 & 100 \\
103 & Cidade Verde - Jd. Imperial & 35,80 & 11 & 75 & 2.702 & 92 \\
609 & Parque Cuiabá - Santa Izabel & 37,50 & 15 & 85 & 3.187 & 88 \\
721 & Voluntários da Pátria - Shopping & & & & & \\
501 & Pantanal & 49,90 & 05 & 36 & 1.796 & 82 \\
613 & Santa Laura - Centro & 41,81 & 02 & 8 & 334 & 73 \\
\hline
\end{tabular}

Fonte: Levantamento realizado pela AMTU em 2019.

As lombadas físicas são ondulações verticais, ou ainda, rampas posicionadas de forma transversal à pista de rolamento, com intuito de diminuir a velocidade dos veículos e permitir a passagem de pedestres conforme definido pelo Conselho Nacional de Trânsito na Resolução $\mathrm{n}^{\mathrm{o}} 600$ (CONTRAN, 2016). Segundo essa Resolução, as ondulações transversais podem ser dispostas desde que haja sinalização apropriada para cada um dos tipos estabelecidos e desde que haja caracterização das mesmas, ou seja, marcações oblíquas inclinadas a $45^{\circ}$ pintadas na cor amarela.

Ainda de acordo com o Resolução no 600(CONTRAN, 2016), o estudo técnico para sua implantação deve contemplar diversos aspectos como o número de pistas, o tipo de ondulação, caracterizações físicas do local, Volume Médio Diário (VMD), velocidade regulamentada, trânsito de pedestres e ciclistas, histórico de acidentes e potencial de riscos no local. Este estudo deve ser realizado por profissional habilitado para tal função. As prerrogativas para a adoção do uso das lombadas são a diminuição da quantidade de acidentes dentro das cidades e a melhoria de segurança para os pedestres, por meio da redução da velocidade dos veículos (CET/ SP, 1992).

As lombadas impactam na velocidade do veículo e as do tipo $\mathrm{B}$, aquelas com 1,5 metros de largura e entre 6 e 8 centímetros de altura, não deveriam estar presentes nos trechos por onde circulam o transporte público coletivo, conforme própria Resolução n ${ }^{\circ} 600$ (CONTRAN, 2016). Nesse sentido, uma investigação sobre como estas lombadas impactam no conforto do usuário e na confiabilidade do sistema de transporte público em virtude de frenagens e acelerações é necessária com vistas a garantir um transporte de qualidade. Conforme aponta Rodrigues (2006), o conceito de qualidade hoje está mais próximo do consumidor do que do produto, ou seja, deve atender aos anseios do consumidor. Trazendo para a realidade do transporte público, não basta apenas que todo o serviço atenda as conformidades técnicas ou que seja feita a entrega do serviço com um nível aceitável de defeitos, importa que as expectativas dos usuários sejam levadas em consideração, como acontece com outros segmentos de atendimento ao público.

Nabuco (2019) argumenta que, se somadas todas as viagens realizadas pelo transporte coletivo, os ônibus chegam a ser submetidos a 5 milhões de passagens por lombadas ao mês, sendo as linhas mais longas aquelas que sofrem mais com este problema. Este fato condiz com as reclamações provindas dos usuários e operadores de transporte em relação à quantidade de lombadas a qual o transporte público é submetido. Em sentido oposto, o estudo conduzido por ANTIĆ et al. (2013) indica que a instalação de lombadas com padrões regulares reduz de fato a velocidade média de tráfego no ponto desejado, mas em uma proporção que não afeta significativamente o nível de serviço da via. 
Lav et al. (2018) mencionam que, muitas vezes, as dimensões padrões das lombadas não são respeitas, destoando da justificativa inicial da implantação das mesmas. Zaidel (1992) comenta que estes dispositivos são controversos devido ao fato de afetarem até mesmo camadas superficiais do pavimento devido à força de tração causada pela frenagem dos veículos no revestimento asfáltico. Além disso, há uma preocupação sobre a utilização excessiva da ondulação transversal como forma de forçar a redução da velocidade de tráfego.

Abdel-Wahed e Hashim (2017) constataram que a largura das lombadas e distância entre estas influencia diretamente na qualidade do pavimento, porém a altura das mesmas não influencia o mesmo. Os autores também mencionam que a variação de velocidade através da aceleração e desaceleração excessivas ocasionadas por ondulações transversais, além de acelerar a deterioração do pavimento, aumenta consideravelmente o tempo de viagem, traz danos aos veículos, desconforto aos passageiros e aumento do consumo de combustível e consequente causa uma maior emissão de gases poluentes.

Lav et al. (2018) defendem que o tamanho ideal de lombadas, para reduzir de forma mais eficiente a velocidade de um veículo sem causar uma aceleração vertical que pode afetar a segurança dos passageiros, é de $30 \mathrm{~cm}$ de largura e $16,8 \mathrm{~cm}$ de altura. Por outro lado, ANTIĆ et al (2013) afirmam que é necessário avaliar a condição da via, através da velocidade regulamentar, atrito lateral, proximidade de pedestres e/ou escolas, dentre outros fatores, fazendo estes dispositivos terem de 3 a $7 \mathrm{~cm}$ de altura, com um padrão de $96 \mathrm{~cm}$ de largura.

Nos últimos anos pode ser identificada uma migração crescente dos usuários do transporte público coletivo para o modo individual, aumentando as externalidades negativas do transporte, como congestionamentos, a poluição sonora e do ar e acidentes. Somente em 2015, houve um decréscimo de $9 \%$ no número de usuários do transporte público coletivo no país, segundo dados da Associação Nacional das Empresas de Transportes Urbanos (NTU, 2016). Em contrapartida, especificamente em Cuiabá, houve um aumento de 2,9\% na frota de automóveis e motocicletas entre 2019 e 2020 (DETRAN, 2020).

Este trabalho busca cobrir uma lacuna encontrada nas pesquisas realizadas, dando o enfoque principal à presença de lombadas nos trajetos dos ônibus e buscando identificar como estas podem afetar a qualidade do transporte público no que tange à segurança dos usuários, ao conforto e ao tempo de viagem. A hipótese inicial é a de que a presença das lombadas piora as viagens realizadas por ônibus, seja no tempo de viagem ou critérios como a qualidade, o conforto e a segurança.

\section{MATERIAIS E MÉTODOS}

O estudo foi realizado na cidade de Cuiabá, capital do estado de Mato Grosso (MT), onde um dos principais meios de transporte coletivo é o ônibus. Segundo a Prefeitura de Cuiabá (2018), são ao todo 101 linhas e a frota total do município é de 383 veículos. Entre 2014 e 2018, foi observada uma redução do número de passageiros no transporte público de $8,1 \%$. Além disso, as viagens têm características pendulares com redução de até $60 \%$ no entre pico (PREFEITURA DE CUIABÁ, 2018). Ela foi dividida em três etapas conforme detalhamento apresentado na sequência (Figura 1). 
Figura 1- Fluxograma das atividades.
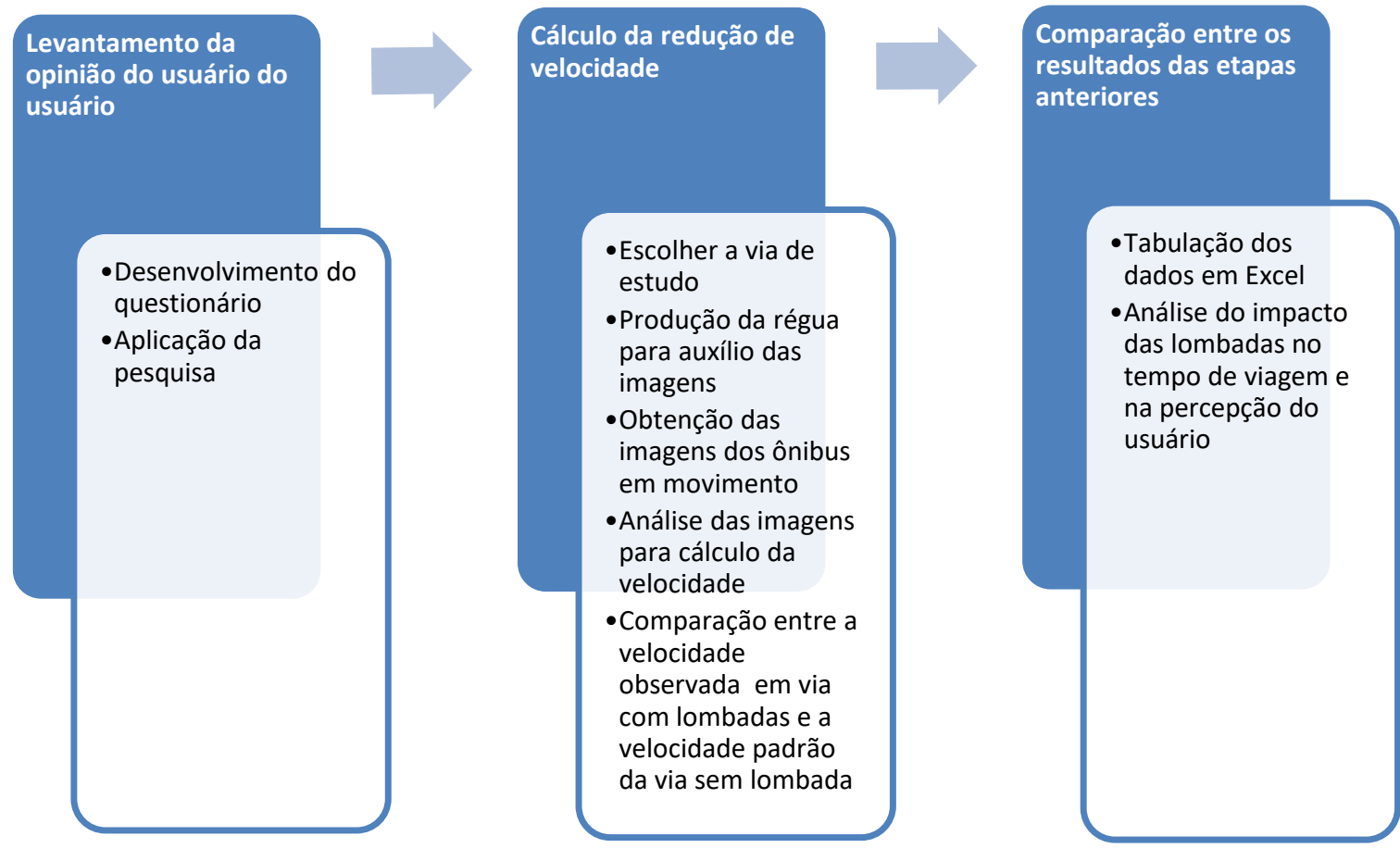

Na primeira etapa foi desenvolvido um questionário para identificar a percepção dos usuários de ônibus em relação às lombadas físicas. Levantou-se o perfil do respondente, por meio do gênero e idade; a linha que mais utiliza, frequência semanal e opinião acerca das lombadas, analisando questões relacionadas à viagem, tais como: tempo de deslocamento, conforto, qualidade geral e segurança (riscos de quedas, quiques e situações semelhantes). A pesquisa com os usuários foi aplicada de duas formas: online e presencial (dentro dos ônibus ou pontos de parada), totalizando 134 entrevistados. O questionário aplicado presencialmente pode ser visualizado na Figura 2.

É válido ressaltar que a maioria das entrevistas foram realizadas de forma presencial, em todos os turnos e em vários pontos de ônibus e terminais, mais especificamente no terminal do CPA III, da Avenida Dante Martins de Oliveira e nos pontos situados no centro de Cuiabá, especialmente na Avenida Tenente Coronel Duarte, em que há muitas linhas distintas, assim como no interior de algumas linhas de ônibus, tais como a 319 (Três Barras), 103 (Jardim Imperial) e 330 (UFMT/ Terminais).

Segundo a Prefeitura de Cuiabá (2018), são realizadas 5.989.269 viagens por mês na capital cuiabana. Ao se considerar que os viajantes realizam viagens de ida e volta, tomando o mês de referência como de trinta dias, a população considerada foi de 99.821 pessoas. A quantidade total de entrevistados foi de 134 pessoas, somadas as entrevistas pessoais às entrevistas online, para um nível de confiabilidade de $90 \%$, a margem de erro da presente pesquisa é de $7,12 \%$. 
Figura 2- Formulário de entrevista presencial.

\begin{tabular}{l} 
Gênero: \\
Idade: \\
Linha utilizada com mais frequência: \\
Frequência com que utiliza esta linha, por semana: \\
Você sente a diferença ao passar por um quebra-mola regular e irregular? \\
Acredita ser mais confortável quando um ônibus passa por uma travessia elevada ao invés de quebra-mola? \\
Qual a interferência que você acredita que as lombadas tenham nas sua viagens de transporte público em relação: \\
\begin{tabular}{|l|l|l|l|l|l|}
\hline $\begin{array}{l}\text { Piora } \\
\text { muito }\end{array}$ & $\begin{array}{l}\text { Piora } \\
\text { pouco }\end{array}$ & Indiferente & $\begin{array}{l}\text { Melhora } \\
\text { pouco }\end{array}$ & $\begin{array}{l}\text { Melhora } \\
\text { muito }\end{array}$ \\
\hline vempo de & & & & & \\
\hline Conforto & & & & &
\end{tabular} \\
\hline Qualidade
\end{tabular}

Na segunda etapa do trabalho foi calculada a redução de velocidade dos ônibus devido à presença de lombadas através de análise automática de imagens obtidas em campo. Para isso, primeiramente definiu-se o tipo de via em que o estudo seria conduzido. Adotou-se os seguintes critérios para a seleção: presença de lombada, ser uma rota de ônibus e não apresentar interferências para o trajeto para obtenção das imagens por meio de Aeronave Remotamente Pilotada (RPA), também conhecida como Drone, tais como árvores e fios de iluminação.

Em seguida, produziu-se uma régua de 20 metros com marcação a cada $50 \mathrm{~cm}$ de extensão, que foi usada como referência de distância para a análise de imagens. Em campo, a régua foi disposta na calçada ao lado do quebra-molas, conforme indicado na Figura 3, e se utilizou um Drone com dispositivo imageador para acompanhar o ônibus por um trajeto de 440 metros. Dessa forma, foi possível obter a velocidade de serviço e a velocidade ao atravessar a lombada. Vale ressaltar que o ônibus estava sem passageiros e a disposição do estudo e que a via escolhida para estudo era uma via local com velocidade máxima de 30 $\mathrm{km} / \mathrm{h}$ e com baixo fluxo de veículos automotores, particulares ou públicos. As imagens obtidas em campo foram submetidas a um processamento automático de imagens, o qual utilizou a régua como referência para os cálculos das distâncias, e o tempo foi obtido através dos tempos do vídeo, isto é, o horário de cada frame analisado, o que permitiu obter velocidades instantâneas do percurso (LUVIZON et al. 2016). 
Correa, E. P.; Baltar, M.; Cavalcante, J.; O impacto das ondulações transversais na qualidade do transporte público coletivo na cidade de Cuiabá, Mato Grosso, Brasil. E\&S - Engineering and Science, 2021, 10:2.

Figura 3 - Imagem do local da pesquisa obtida por meio do Drone com a régua usada como referência.

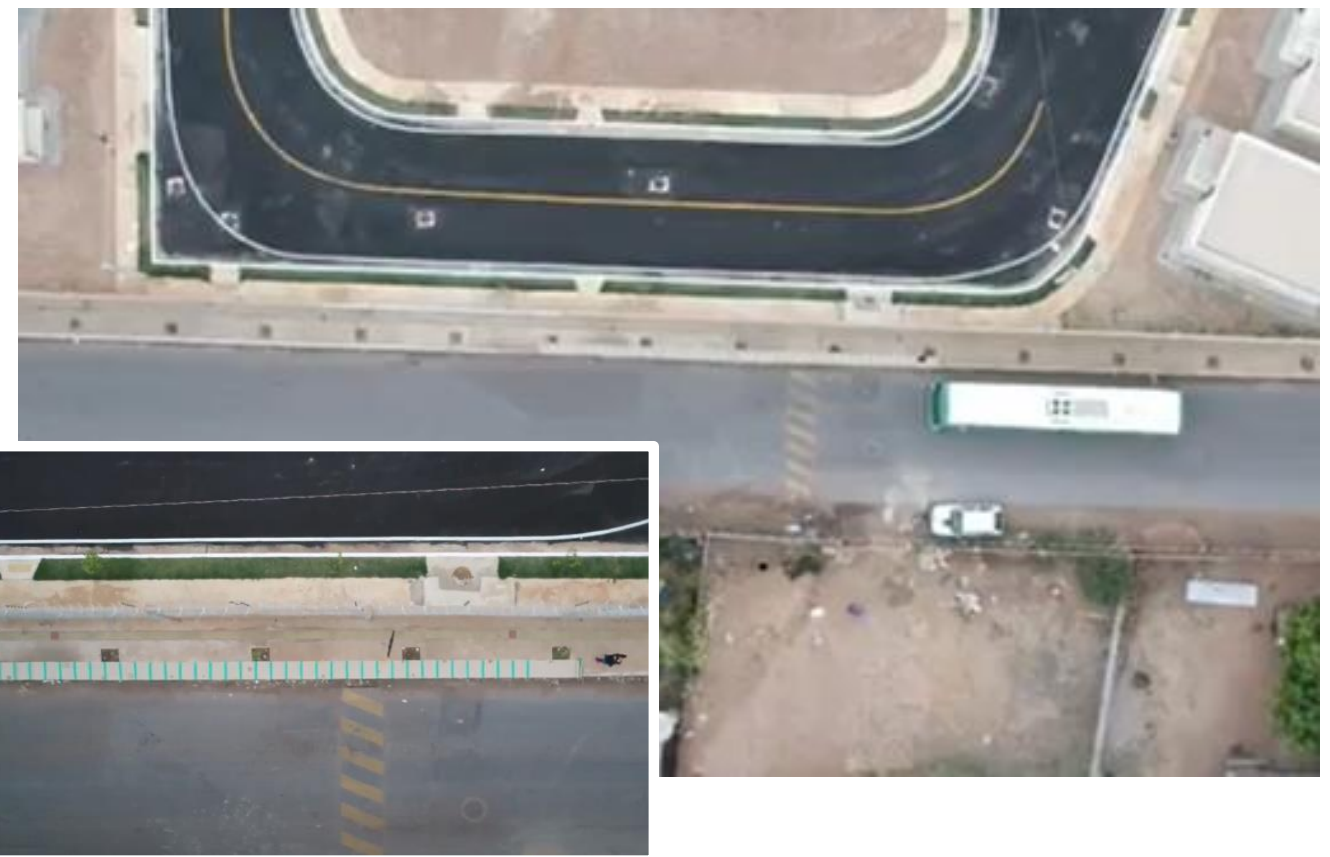

A terceira etapa consistiu na análise e comparação entre os dados obtidos pela pesquisa de opinião dos usuários, obtidos na primeira etapa, e os dados da experiência em campo, obtidos na segunda etapa. A tabulação dos dados foi feita com auxílio do programa Excel e o tratamento deles foi realizado no software Power BI, importante ferramenta para criação de relatórios e exploração dos dados de maneira mais interativa (MICROSOFT, 2021), conforme ilustrado na figura 4.

Figura 4 - Imagem da interface do query, modelagem e relatório do Power BI.

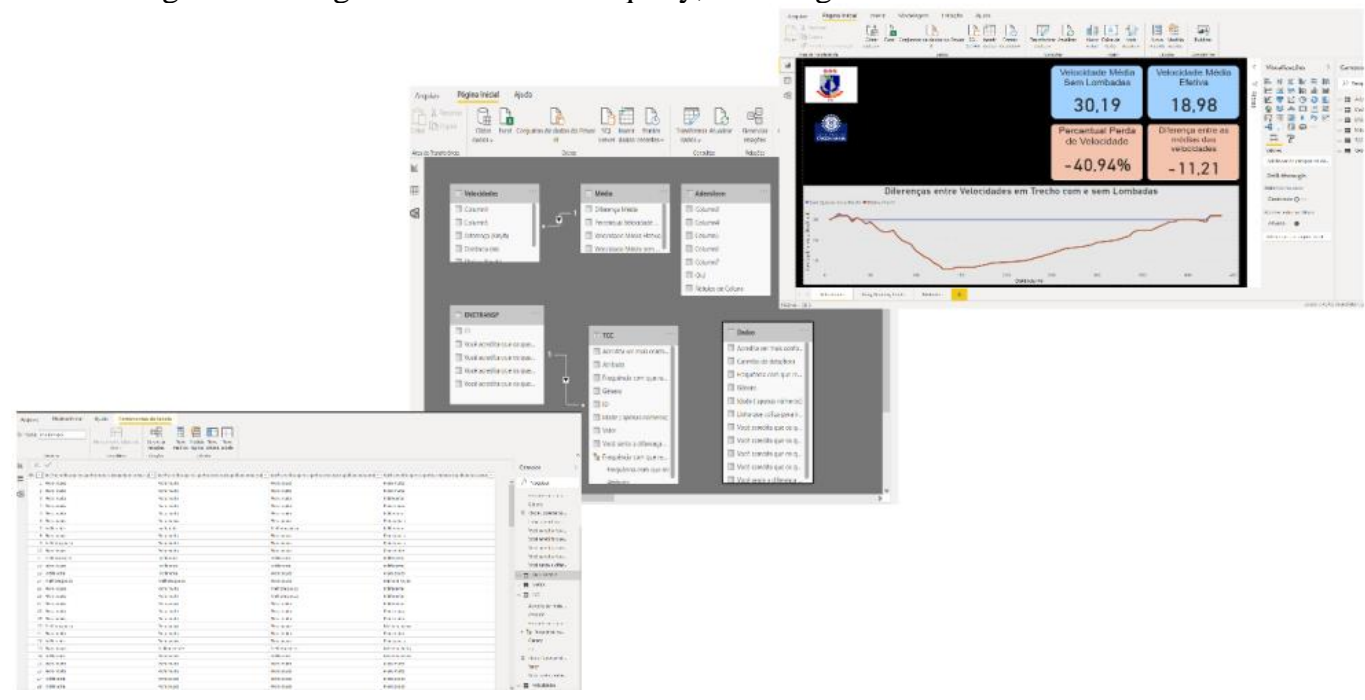

\section{RESULTADOS/ DISCUSSÕES}

A média de idade dos entrevistados foi de 29 anos, sendo que a maioria eram mulheres (Figura 5). O fato delas serem a maioria dentro dos ônibus reflete dois aspectos importantes da nossa sociedade. O primeiro é que as mulheres possuem menor poder aquisitivo em relação aos homens conforme pesquisa realizada pelo Departamento Intersindical de Estatística e Estudos Socioeconômicos (DIEESEL, 2013), e o outro é que recebem menores salários, apesar de ocuparem cargos semelhantes. Ainda segundo esta pesquisa, as mulheres 
Correa, E. P.; Baltar, M.; Cavalcante, J.; O impacto das ondulações transversais na qualidade do transporte público coletivo na cidade de Cuiabá, Mato Grosso, Brasil. E\&S - Engineering and Science, 2021, 10:2.

realizam mais viagens, pois além das viagens devido ao estudo e trabalho, elas também acompanham os filhos em suas atividades.

Figura 5: Classificação por gênero.

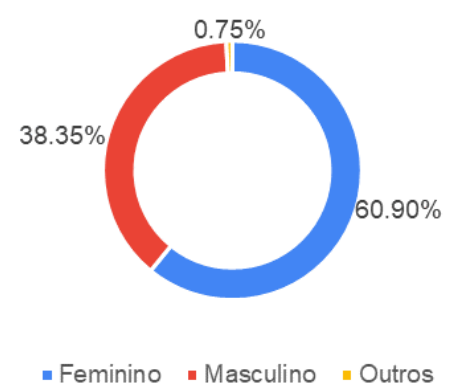

É importante entender qual a frequência com que o usuário utiliza o transporte público (Figura 6), uma vez que este fato pode refletir diretamente na forma como ele enxerga esta experiência, pois ela é mais marcante para aqueles que fazem uso diariamente em relação àqueles que utilizam esporadicamente. Nesse sentido, cerca de $67 \%$ dos entrevistados são usuários frequentes do transporte público e o utilizam cinco ou mais dias durante a semana. Em linhas gerais, a motivação do deslocamento está relacionada ao trabalho e estudo. Analisando o público feminino, observa-se que $51 \%$ delas utilizam o transporte público entre 3 e 7 dias na semana, já 64\% dos homens entrevistados utilizam cinco vezes por semana ou mais.

Figura 6: Frequência de viagens durante a semana.

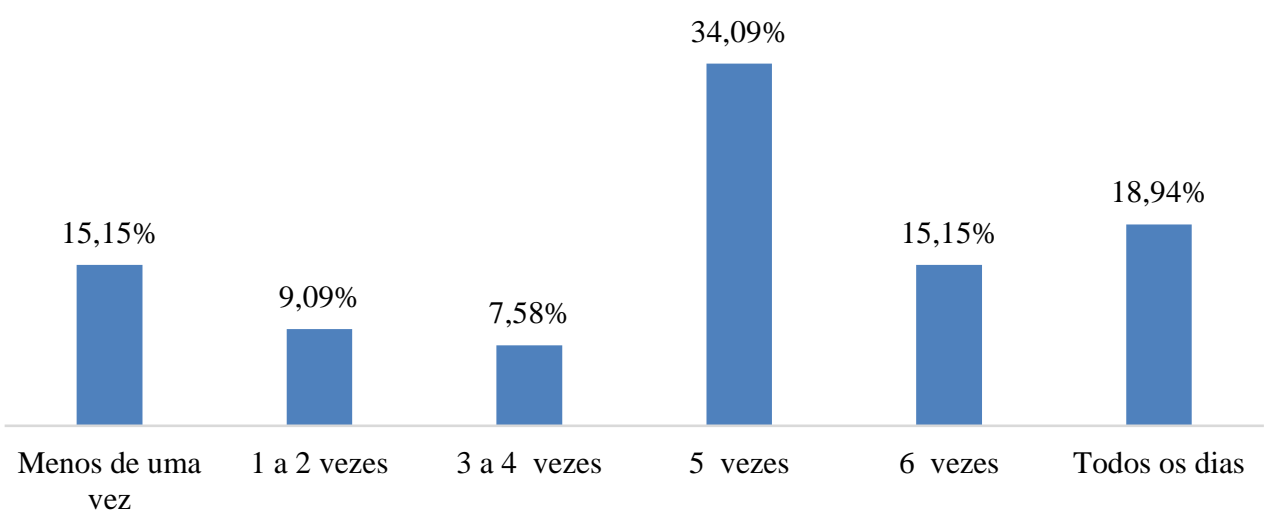

A Figura 7 apresenta a as respostas dos usuários durante as viagens por ônibus, tomando-se como referência como as lombadas existentes nos trajetos afetam a sua percepção quanto a segurança, o conforto e o tempo de viagem. Observou-se durante as entrevistas presenciais que a população desconhece as formas adequadas de adoção das lombadas. Nessas entrevistas houve a necessidade de apresentar figuras ou mesmo fornecer mais informações verbais para melhor entendimento dos entrevistados do que era ou não uma lombada regular. Foi possível observar também que os usuários associam a quantidade excessiva de lombadas nas vias a necessidade de proporcionar segurança aos pedestres, já que as lombadas trazem redução de velocidade. 
Correa, E. P.; Baltar, M.; Cavalcante, J.; O impacto das ondulações transversais na qualidade do transporte público coletivo na cidade de Cuiabá, Mato Grosso, Brasil. E\&S - Engineering and Science, 2021, 10:2.

Figura 7 - Respostas de acordo com os atributos indicados no questionário da pesquisa.

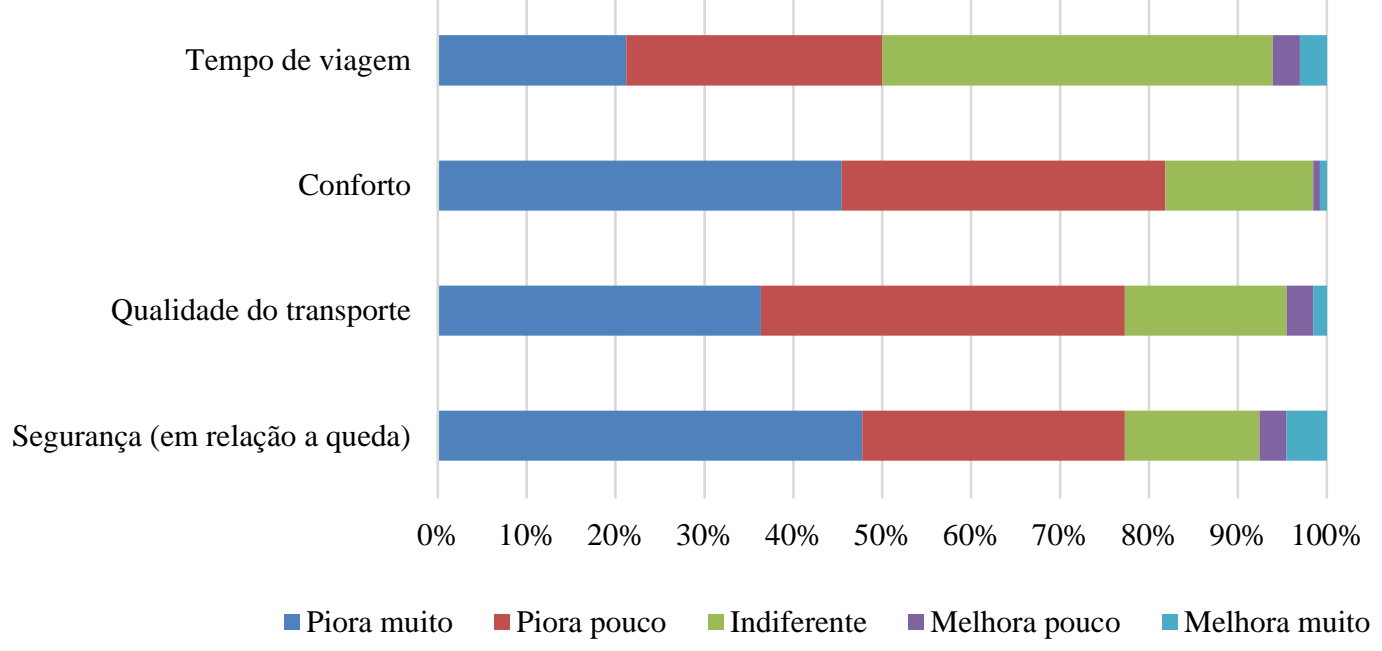

Dos quesitos estudados, o tempo de viagem foi aquele que os usuários colocaram como o menos impactado pela presença de lombadas. Diversos entrevistados argumentaram que o aumento do tempo de viagem é justificado pela sensação de segurança trazida por esse dispositivo para os pedestres. Essa explicação dada durante as entrevistas corrobora com a existência de uma quantidade elevada desses dispositivos dentro dos bairros, mesmo que irregulares, pois gera na população uma maior sensação de segurança ao usar a via como pedestres.

Entretanto, quando questionados sobre como se sentem em relação aos demais critérios, o conforto da viagem foi o quesito com pior aprovação $(81,8 \%)$, seguido de segurança $(77,3 \%)$ e qualidade geral da viagem $(77,3 \%)$. Observou-se nas entrevistas feitas presencialmente, que muitos daqueles que têm opinião indiferente quanto aos critérios de conforto, qualidade e segurança, justificaram que o primeiro está mais relacionado com a forma com que o veículo é conduzido, ou seja, com a velocidade adotada nas proximidades das lombadas ou travessias elevadas que resultam em freadas bruscas, por exemplo. Portanto, entre os entrevistados, observou-se que eles acreditam que o desconforto e o risco de queda dentro dos ônibus são consequências de uma condução inadequada por parte dos motoristas, não atribuindo assim tanto peso às lombadas.

Uma outra justificativa para as respostas "indiferente", especialmente para os atributos de conforto e tempo de viagem foi a frequência com que o entrevistado utiliza o serviço. Ao se conduzir uma análise mais detalhada no banco de dados considerando a frequência de viagens semanais dos usuários, nota-se que os usuários menos assíduos não sentem tanto desconforto quando comparados àqueles que usam os ônibus cinco ou mais vezes na semana. Por exemplo, no quesito conforto (Figura 8), 50\% dos usuários consideraram a presença de lombadas indiferentes, enquanto para os usuários que utilizam o transporte público cinco vezes ou mais, essa razão se reduz para apenas $12 \%$. 
Figura 8 - Respostas do atributo conforto por frequência de viagens semanais.

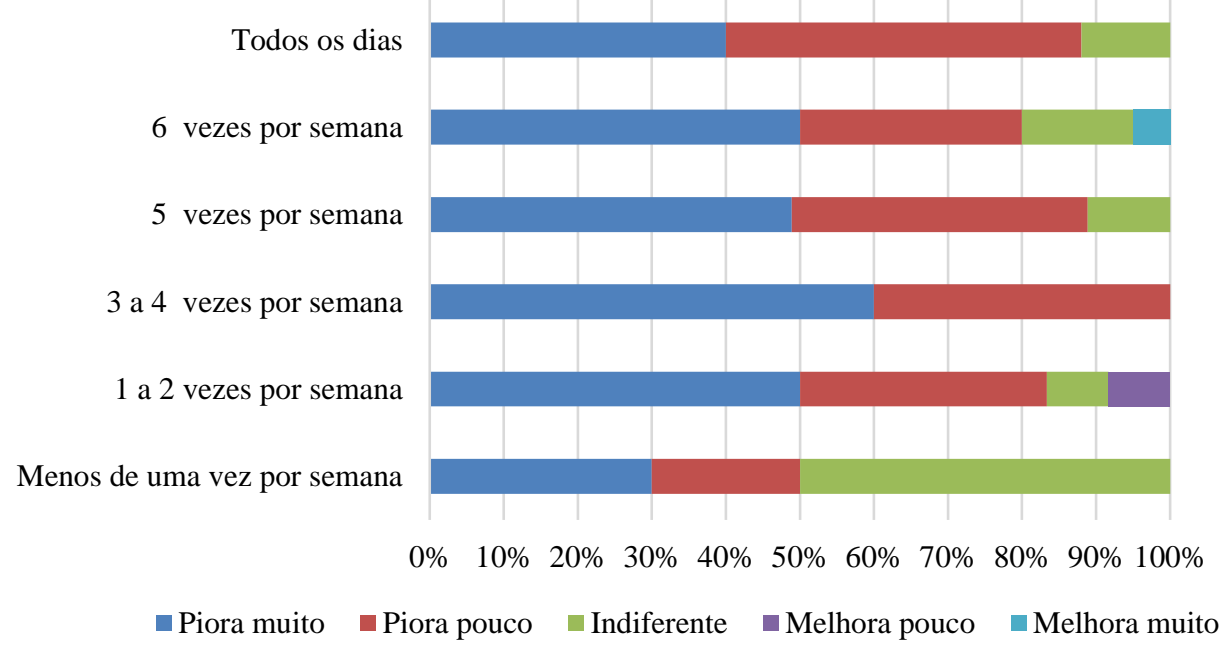

Fazendo-se a mesma abordagem anterior agora para o quesito tempo de viagem (Figura 9), os viajantes que realizam viagens diariamente foram os que demonstraram observar maior impacto das lombadas, uma vez que $72 \%$ destes responderam que a presença delas piora muito ou piora pouco o tempo de viagem, enquanto apenas $24 \%$ consideraram que elas são indiferentes. Já para aqueles que viajam entre 3 ou 4 vezes na semana, a porcentagem que consideram indiferente sobe para 57\%. Portanto, nota-se que a frequência de viagem é um fator ajuda explicar a percepção dos usuários quanto ao maior ou menor impacto das lombadas.

Figura 9 - Respostas do atributo tempo de viagem por frequência de viagens semanais.

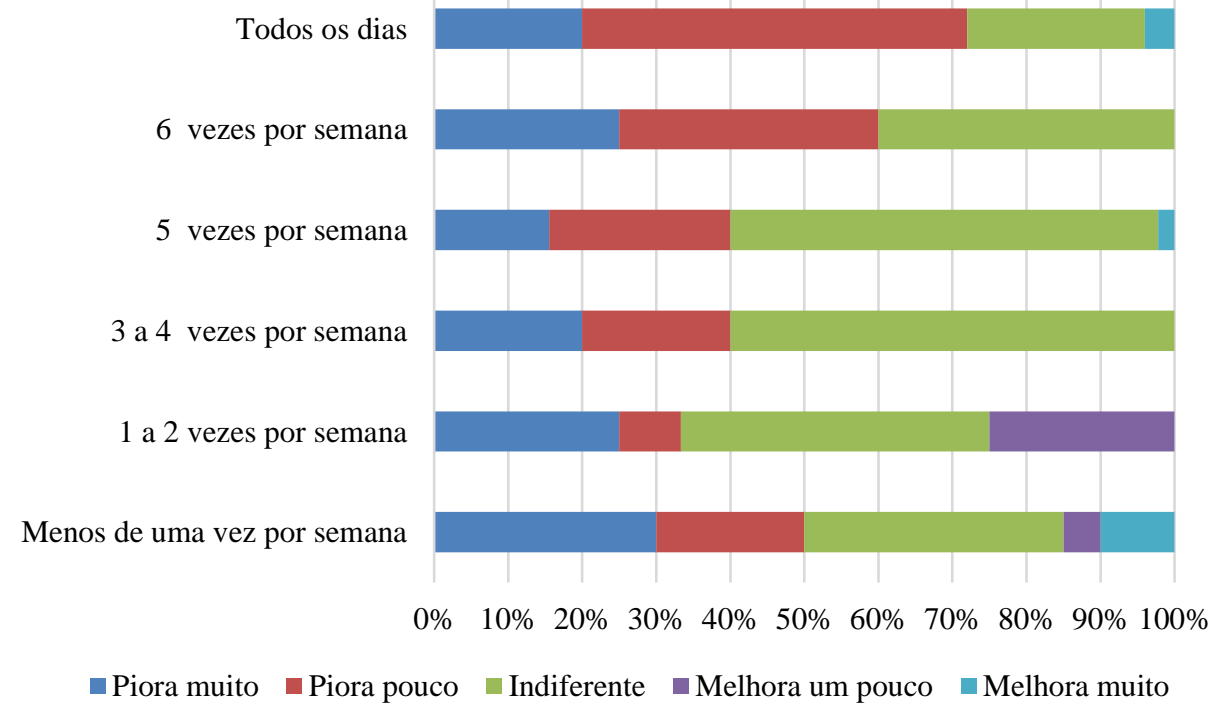

Outro ponto a ser relatado, é que os usuários têm sensações de desconforto diferentes dependendo do tipo de ondulação transversal existente na via. Estes relatam sentir diferentes percepções ao passar pelas travessias regulares, irregulares e elevadas, (Figura 10). Os entrevistados que responderam não sentir diferença entre as lombadas relataram de forma informal que existem motoristas que "atropelam os quebra-molas", tornando qualquer tipo de ondulação transversal desconfortável. Além disso, fica visível a cultura de que a implantação 
Correa, E. P.; Baltar, M.; Cavalcante, J.; O impacto das ondulações transversais na qualidade do transporte público coletivo na cidade de Cuiabá, Mato Grosso, Brasil. E\&S - Engineering and Science, 2021, 10:2.

desses dispositivos é a solução para o problema relacionado aos riscos vivenciados pelos pedestres que transitam pela cidade.

Figura 10 - Sensação em diferentes ondulações transversal.

Você acredita a travessia elevada é mais confortável

Você sente a diferença entre passar por uma lombada do que lombada?

regular e uma lombada irregular?
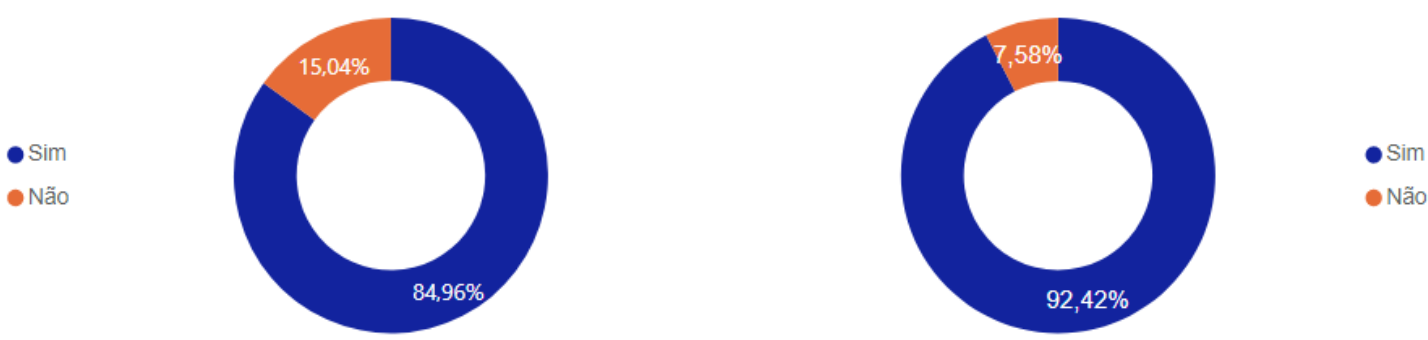

$\mathrm{Na}$ segunda etapa da pesquisa, conduziu-se um experimento onde um drone acompanhou a passagem de um ônibus por uma lombada irregular em uma via local, utilizada como itinerário de linhas de ônibus regulares, com velocidade regulamentada de $30 \mathrm{~km} / \mathrm{h}$. Destaca-se que as imagens permitem mensurar as velocidades ao longo do trecho, o que é importante para quantificar o impacto da existência delas no tempo de viagem. O drone acompanhou o ônibus por cerca de 440 metros, possibilitando analisar, por meio do software de leitura das imagens, a velocidade de serviço anterior a visualização das lombadas, durante a frenagem que antecede a atravessar da mesma e posterior aceleração do veículo até a retomada da velocidade de serviço conforme ilustrado na Figura 11. A menor velocidade constatada pela análise de imagens foi de $6 \mathrm{~km} / \mathrm{h}$ exatamente durante a passagem pela lombada.

Figura 11 - Análise da velocidade do ônibus antes, durante e posteriormente a travessia da lombada.

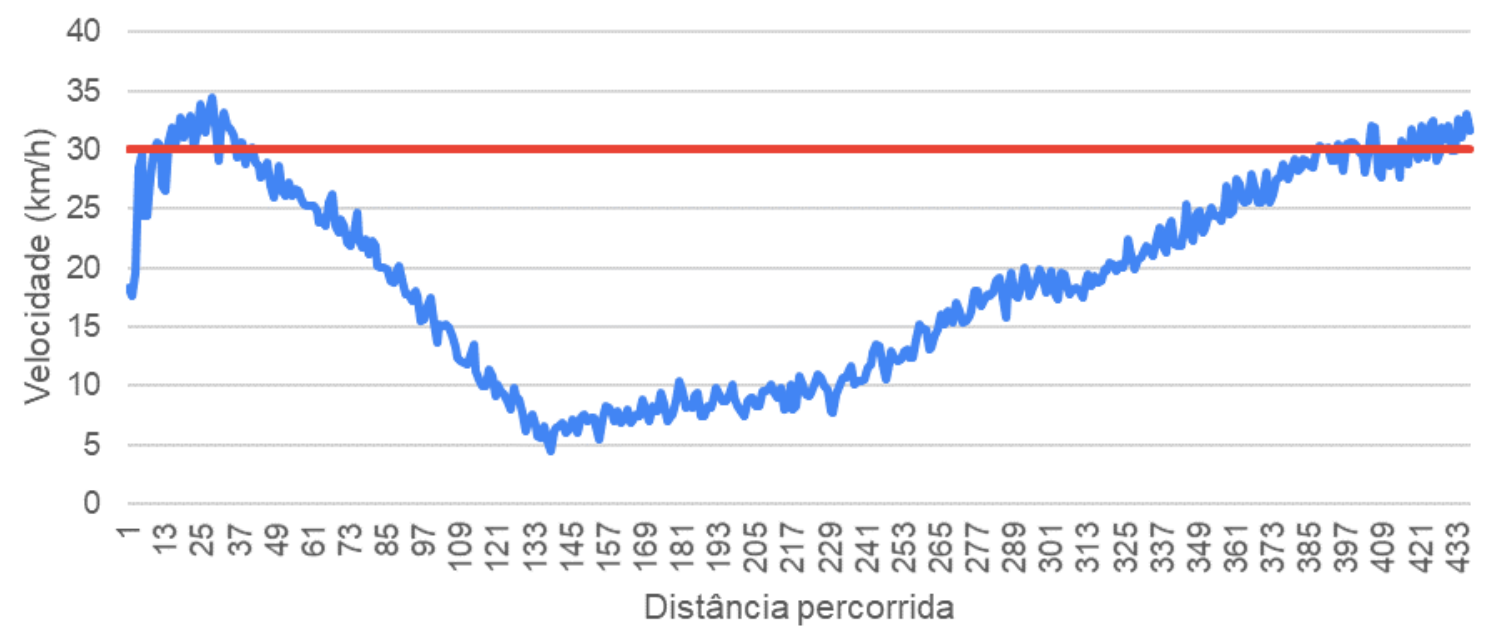

Veocidade obtida em campo $\quad$ Velocidade regulamentada

Ao relacionar os resultados obtidos através das respostas dos usuários com aqueles adquiridos por meio das imagens captadas, constata-se que, embora os usuários não sintam alteração no seu tempo de viagem, há uma queda significativa da velocidade média, afetando a duração do deslocamento. Portanto, a velocidade média de serviço que era de $30 \mathrm{~km} / \mathrm{h}$ se 
reduz para $11,21 \mathrm{~km} / \mathrm{h}$ nos trechos analisado que considera a retomada da velocidade de serviço, o que representa uma redução de $40,94 \%$ devido a presença de lombadas.

$\mathrm{Na}$ terceira etapa, ao relacionar as respostas obtidas com os resultados referentes ao aumento no tempo de deslocamento, é possível afirmar que as lombadas podem impactar indiretamente nos demais atributos estudados, isso porque, uma viagem com duração maior também é mais cansativa e estressante. Lembrando que a dimensão tempo reflete no aumento dos gastos com combustível, manutenção dos veículos, desconforto para passageiros no interior seja de carros, ônibus, motocicletas ou mesmo bicicletas.

Portanto, observa-se que os usuários realmente acreditam que a presença das lombadas impacta na qualidade do serviço como todo e, apesar do quesito tempo de viagem ser o que os usuários citaram como o menos impactado pelas lombadas. Porém, como verificado pela análise das imagens obtidas pelo drone, há a comprovação de que o impacto é significativo. Ele se torna ainda mais significativo quando se considera todas as lombadas existentes no trajeto que o ônibus percorre diariamente.

\section{CONCLUSÃO/ CONSIDERAÇÕES FINAIS}

O trabalho analisou os impactos causados pelas lombadas na qualidade do serviço de transporte público coletivo oferecido para o usuário, utilizando como estudo de caso a cidade de Cuiabá - MT. A hipótese levantada inicialmente de que a presença das ondulações transversais ocasiona a diminuição no tempo de viagem e piora a sensação de conforto e de segurança da viagem sentida pelos usuários foi comprovada através da metodologia proposta.

A sensação experimentada pelos usuários depende de vários fatores como a idade, gênero, regularidade no uso do transporte público. Dessa forma, analisar, quantificar e tomar as melhores decisões com relação ao transporte público é uma tarefa multidisciplinar e complexa, exigindo estudos aprofundados sobre muitos outros temas que acabam interferindo na forma como a qualidade é percebida e na forma como as expectativas dos usuários são construídas. Nas entrevistas realizadas com os usuários observou-se que os usuários frequentes são os que mais relatam o impacto das lombadas em seus trajetos. Além disso, demonstraram sentir diferença ao percorrer os diferentes tipos de ondulação, mostrando a importância da construção delas dentro das normas previstas pelo Conselho Nacional de Trânsito na Resolução (CONTRAN), devendo as mesmas serem utilizadas apenas quando forem realmente necessárias.

A partir da captação de imagens por meio de drone foi possível mensurar as perdas de velocidades causadas pela presença de ondulações transversais, o que demonstra seu impacto não somente no tempo de viagem. Com as respostas do questionário foi possível concluir que elas também afetam o conforto das viagens a partir do ponto de vista do usuário do transporte público.

Nota-se, portanto, que tanto as lombadas quanto as travessias elevadas jamais devem ser admitidas como solução única para reduzir a velocidade de trânsito, devendo outras medidas serem estudadas e implantadas. Tais estudos e definições devem ser realizados por profissionais habilitados para esta finalidade. Cita-se aqui, a título de exemplo, o conceito de ruas completas que promovem tanto a segurança viária quanto o conforto a todos os usuários da via, independente do modo de transporte utilizado.

Como sugestão para trabalhos futuros podem ser realizadas abordagens com drones em trajetos maiores com vistas a poder se ter um comportamento mais realístico, assim como estudos comparativos de perdas de desempenho para outros tipos de veículos ou ainda o estudo de fatores que geram maiores gastos relacionados com manutenção dos veículos que passam por trajeto com muitas lombadas, de forma análoga para carros de passeios, 
Correa, E. P.; Baltar, M.; Cavalcante, J.; O impacto das ondulações transversais na qualidade do transporte público coletivo na cidade de Cuiabá, Mato Grosso, Brasil. E\&S - Engineering and Science, 2021, 10:2.

motocicletas e bicicletas. Pode0se ainda ser comparados os diferentes impactos de acordo com os tipos de lombadas encontradas nas vias.

\section{REFERÊNCIAS}

ABDEL-WAHED, Talaat Ali; HASHIM, Ibrahim Hassan. Effect of speed hump characteristics on pavement condition. Journal of traffic and transportation engineering (English edition), v. 4, n. 1, p. 103-110, 2017. Disponível em: < https://www.sciencedirect.com/science/article/pii/S2095756416300216> Acesso em: 16 de maio de 2019.

AMTU- ASSOCIAÇÃO MATOGROSSENSE DE TRANSPORTE URBANO- 2019. Disponível em : <https://amtu.com.br/o-futuro-do-transporte-publico-depende-de-nosartigo/ > Acesso em: 27/09/2019.

ANTIĆ, Boris et al. The influence of speed bumps heights to the decrease of the vehicle speed-Belgrade experience. Safety Science, v. 57, p. 303-312, 2013. 21 de maio de 2019.

CET/ SP- Companhia de Engenharia de Trafego de São Paulo. A influência de dispositivos redutores de velocidade no desempenho do transporte coletivo urbano por ônibus. 1992. São Paulo. Disponível em: http://www.cetsp.com.br/media/20635/nt158.pdf Acesso em: 04/08/2019.

CONTRAN- Conselho Nacional de Trânsito. Resolução 600. 2016. Disponível em: $<$ https://infraestrutura.gov.br/resolucoes-contran.html> Acesso em 21/05/2019.

CONTRAN- Conselho Nacional de Trânsito. Resolução 738. 2018. Disponível em: <https://infraestrutura.gov.br/images/Resolucoes/Resolucao7382018.pdf> Acesso em $01 / 03 / 2020$.

CTB- CÓDIGO BRASILEIRO DE TRÂNSITO. LEI N ${ }^{\circ}$ 13.281, DE 4 DE MAIOR DE 2016, ART. 61. Disponível em: < http://www.planalto.gov.br/ccivil_03/leis/L9503.htm> Acesso em: 04/10/2019.

CUPOLILLO, Maria Teresa Araujo. Estudo de Medidas Moderadoras do Tráfego com o Objetivo de Reduzir a Velocidade e os Conflitos nas Travessias Urbanas Rio de Janeiro. 2006 (COPPE/UFRJ, M.Sc. Engenharia de Transportes, 2006) DISSERTAÇÃO Universidade Federal do Rio de Janeiro, COPPE. Disponível em: $<$ http://redpgv.coppe.ufrj.br/index.php/pt-BR/producao-da-rede/dissertacoes-eteses/2006/102-maria-cupolillo-estudo-de-medidas-modradoras-do-trafego-msc-ufrj-2006/file $>$ Acesso em: 01/10/2019.

DETRAN (2020) Demonstrativo da frota de veículos por tipo - Mato Grosso, Cuiabá e demais cidades. Disponível em: https://www.detran.mt.gov.br/veiculos1. Acesso em junho de 2021.

DIEESEL, 2013. A Inserção da Mulher no Mercado de Trabalho. Disponível em: < https://www.dieese.org.br/analiseped/2013/2013pedmulhermet.pdf > Acesso em 12 de julho de 2020.

FERRAZ, Antônio Pinto; TORRES, Isaac Guilhermo Espinosa.Transporte público urbano$2^{a}$ ed . rev. e atual.- São Carlos, editora: RiMa, 2004. 428p 
Correa, E. P.; Baltar, M.; Cavalcante, J.; O impacto das ondulações transversais na qualidade do transporte público coletivo na cidade de Cuiabá, Mato Grosso, Brasil. E\&S - Engineering and Science, 2021, 10:2

LAV, A. Hakan; BILGIN, Ertugrul; LAV, A. Hilmi. A fundamental experimental approach for optimal design of speed bumps. Accident Analysis \& Prevention, v. 116, p. 53-68, 2018. 17 de maio de 2019.

LUVIZON, D. C.; NASSU, B. T.; MINETTO, R. A video-based system for vehicle speed measurement in urban roadways. IEEE Transactions on Intelligent Transportation Systems, IEEE, v. 18, n. 6, p. 1393-1404, 2016

MICROSOFT (2021) Power BI. Disponível em: https://powerbi.microsoft.com/ptbr/downloads/. Acessado em junho de 2021.

NABUCO, Laura. Até 128 lombadas no trajeto: saiba por que o tempo de espera pelo ônibus só aumenta em Cuiabá. O Livre, Cuiabá, 27 de set. de 2019. Disponível em: $<$ https://olivre.com.br/ate-128-lombadas-no-trajeto-saiba-por-que-o-tempo-de-espera-peloonibus-so-aumenta-em-cuiaba> Acesso em: 27/09/2019.

NTU- Associação Nacional das Empresas de Transportes Urbanos. Anuário 2017/2018. 2018. Brasília-DF. Disponível em: <https://www.ntu.org.br/novo/upload/Publicacao/Pub636687203994198126.pdf >Acesso em:10/07/2019.

NTU- Associação Nacional das Empresas de Transportes Urbanos. Ônibus perde 3 milhões de passageiros por dia no Brasil. 2016. Revista NTU urbano. ISSN: 2317-1960 Ano IV, $\begin{array}{lllllll}\text { Número } & 23 & \text { Set } & / & \text { Out } & 2016\end{array}$ http://www.ntu.org.br/novo/upload/Publicacao/Pub636120575837109247.pdf>. Acesso em 10/07/2019.

ONU-Habitat. Mobility. Disponível em: <http://UN-HABITAT.org/urban-themes/mobility/>. Acessado em 20 de julho de 2016.

PREFEITURA DE CUIABÁ (2018) Concessão do Serviço de Transporte Coletivo Público Municipal - AUDIÊNCIA PÚBLICA de 19 de dezembro de 2018.

RODRIGUES, Maurício Olbrick. Avaliação da qualidade do transporte coletivo da cidade de São Carlos. 2006. Dissertação (Mestrado em Transportes) - Escola de Engenharia de São Carlos, Universidade de São Paulo, São Carlos, 2006. doi:10.11606/D.18.2006.tde-26072006211449. Acesso em: 04/06/2019.

TRB (2010) Highway Capacity Manual, Transportation Research Board, EUA.

ZAIDEL, D.; HAKKERT, Alfred-Shalom; PISTINER, A. H. The use of road humps for moderating speeds on urban streets. Accident Analysis \& Prevention, v. 24, n. 1, p. 45-56, 1992. 16 de maio de 2019. 